\title{
CD10 Immunohistochemical Expression in Apocrine Lesions of the Breast
}

\author{
Bence Kővária Ágnes Báthori ${ }^{\mathrm{a}}$ Gábor Cserni ${ }^{\mathrm{a}, \mathrm{b}}$

 \\ Teaching Hospital, Kecskemét, Hungary
}

\section{Key Words}

Breast cancer $\cdot \mathrm{CD} 10 \cdot$ Apocrine adenosis - Ductal carcinoma in situ

\begin{abstract}
Objective: In the breast, CD10 is expressed by myoepithelial cells (MECs), and apocrine metaplasia has also been mentioned as being positive with this marker. Apocrine lesions have been explored for the expression of CD10. Methods: The apocrine lesions studied included 11 cysts, 6 cases of apocrine adenosis, 2 of apocrine metaplasia or hyperplasia in papilloma, 13 ductal carcinomas in situ (DCIS) and invasive carcinomas (14 ductal and 4 lobular). Results: Benign apocrine lesions showed complete or partial luminal CD10 staining, although most cases included parts without staining, and 2 lesions were completely negative. The MECs were often but not always positive. Nine of the 13 cases of apocrine DCIS displayed no luminal staining, but 4 demonstrated very focal luminal positivity. The MECs around the DCIS showed a spectrum of staining from nil to strong and complete. Only 4 invasive carcinomas demonstrated luminal/membranous staining. Cytoplasmic CD10 positivity was seen focally in 4 invasive cancers and in 3 DCIS. Conclusion: CD10 positivity is luminal/membranous in most benign apocrine lesions, the staining being nonuniversal and sometimes focal. Analo-
\end{abstract}

gous staining in apocrine malignancies seems rarer in DCIS and even rarer in invasive apocrine carcinomas, but atypical cytoplasmic positivity may also occur. CD10 is not an ideal myoepithelial marker in apocrine lesions.

(c) 2015 S. Karger AG, Basel

\section{Introduction}

Cluster differentiation 10 (CD10) also known as neprilysin, enkephalinase, common acute lymphoblastic leukemia antigen (CALLA), membrane metalloendopeptidase (MME) or neutral endopeptidase (NEP) is a membrane-bound zinc-dependent metalloprotease enzyme that degrades a number of small secreted peptides $[1,2]$.

It is a fairly ubiquitous enzyme found on the surface of many different cell types including pre-B cells, germinalcenter B cells, neutrophils, T-cell precursors and epithelial cells of the kidney, stomach, colon, prostate and liver canaliculi as well as in stromal cells of the endometrium and myofibroblasts [3]. In humans, CD10-related DNA sequences are found on chromosome 3 [4]. Three different splice variants of CD10 have been identified, suggesting that CD10 expression may be controlled in a tissuespecific manner [5].

\section{KARGER 125}

(c) 2015 S. Karger AG, Base

$1015-2008 / 15 / 0826-0259 \$ 39.50 / 0$

E-Mail karger@karger.com

www.karger.com/pat
Bence Kővári

Department of Pathology, University of Szeged

Állomás u. 2

HR-6720 Szeged (Hungary)

E-Mail kovari.bence.p@gmail.com 
Physiologically, CD10 plays an important role in the metabolism of signaling peptides like natriuretic peptides, angiotensins, bradykinin, endothelin, enkephalins, oxytocin, tachykinins, substance $P$, calcitonin gene-related peptide (CGRP) and vasoactive intestinal polypeptide (VIP), involving it in the extracellular regulation of a number of signaling pathways of the mammalian nervous, cardiovascular, inflammatory and immune systems $[1,3]$.

CD10 is involved in the pathogenesis of numerous nonneoplastic diseases such as diabetic nephropathy [6] and Alzheimer's disease [7]. With immunohistochemistry (IHC), it can be detected in many hematological malignancies [8-10], soft tissue neoplasia (e.g. pleiomorphic undifferentiated sarcoma, fibrosarcomas, leiomyosarcomas and malignant peripheral nerve sheath tumors) [11] as well as in carcinomas of different organs, like the skin [12, 13], lung [14], pancreas [15], liver [16], stomach [17], cervix [18], kidney [19], bladder [20] and prostate [21]. Such a wide spectrum of expression may suggest a limitation in the usefulness of CD10 immunostaining in routine diagnostic pathology.

As concerns the breast, CD10 has an important role in its development through modulation of cell growth and differentiation, and by having effects on epithelial-mesenchymal morphogenesis [22, 23]. CD10 is not only expressed by myoepithelial cells (MECs) but can also be detected on the surface of mammary stem cells, early common breast progenitor cells and in myoepithelial progenitors. CD10 protease maintains the early progenitor population in the human mammary lineage by degrading signaling proteins that would otherwise promote maturation [24]. A study using a mouse model has shown the involvement of oxytocin, a peptide cleaved by CD10, in the differentiation of MECs [25].

CD10 also has prognostic implications; its expression in breast tumor stromal cells is correlated with estrogen receptor (ER) negativity, a higher grade and poor prognosis $[26,27]$. CD10 has been shown to discriminate between benign, borderline and malignant phyllodes tumors of the breast and its expression has been found on IHC to correlate significantly with the occurrence of distant metastasis [28].

In diagnostic breast histopathology, CD10 IHC is used to identify MECs. Although MECs around normal structures (ducts and lobules) are nicely highlighted by this marker, in pathologic conditions such as ductal carcinoma in situ (DCIS), CD10 has a relatively low sensitivity as an MEC marker [29], and its specificity also seems compromised by the fact that, rarely, tumor cells also stain with the antibody [30], although the pattern of staining in

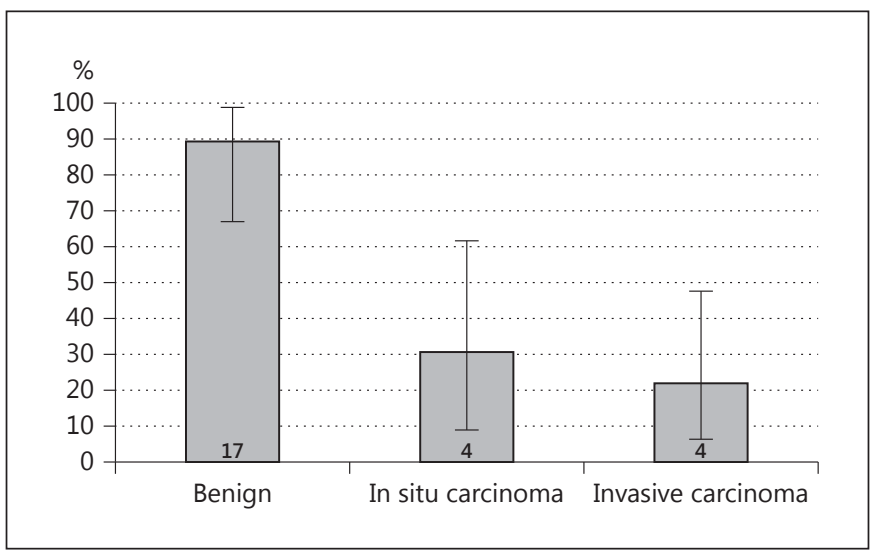

Fig. 1. Proportion of benign lesions, in situ and invasive cancers showing luminal/membranous CD10 positivity. The bars represent $95 \%$ CIs.

the neoplastic mammary epithelium has not been widely studied.

Apocrine epithelium has been described to be positive for CD10 [31] and Kalof et al. [29] clearly documented the consistent luminal staining of apocrine metaplasia. While studying breast lesions immunostained for CD10 as an MEC marker, we also recognized that paratumoral apocrine cysts demonstrated a strong, predominantly apical reaction, and we have also found traces of this staining pattern in the literature $[29,31]$. To our knowledge, no previous studies have systematically examined CD10 expression of apocrine lesions. In this study, we analyzed a series of breast lesions with apocrine differentiation for the expression of CD10, both in the epithelial and the myoepithelial components. The aim was to explore how the immunostaining varied in benign, in situ and invasive malignant lesions.

\section{Materials and Methods}

In this retrospective study, tissue blocks of 50 breast lesions from the archives of the Department of Pathology at the University of Szeged and the Bács-Kiskun County Teaching Hospital were used. The antibody used was a mouse monoclonal antibody (clone 56C6, ready to use; Dako, Glostrup, Denmark or Cell Marque, 1:50 dilution; Rocklin, Calif., USA).

Following the instructions of the manufacturer, IHC stainings were carried out on 44 sections of whole tissue (thickness: $4-5 \mu \mathrm{m}$ ) and tissue microarray. Different chromogens were used in the two departments (diaminobenzidine, Dako or Nova RED or VIP, Vector Laboratories, Burlingame, Calif., USA).

Statistical calculations were made with GraphPad QuickCalcs, (San Diego, Calif., USA). 
Fig. 2. Examples of CD10 positivity in different lesions. a Apocrine cysts with areas of papillary hyperplasia. Note focal to nearcomplete luminal epithelial and strong myoepithelial positivity. b DCIS with a lack of luminal/membranous staining in foci of lumen formation and weak myoepithelial labeling. c Luminal and strong cytoplasmic staining in invasive carcinoma of no special type. d Very focal cytoplasmic labeling in invasive carcinoma. $\times 10$.

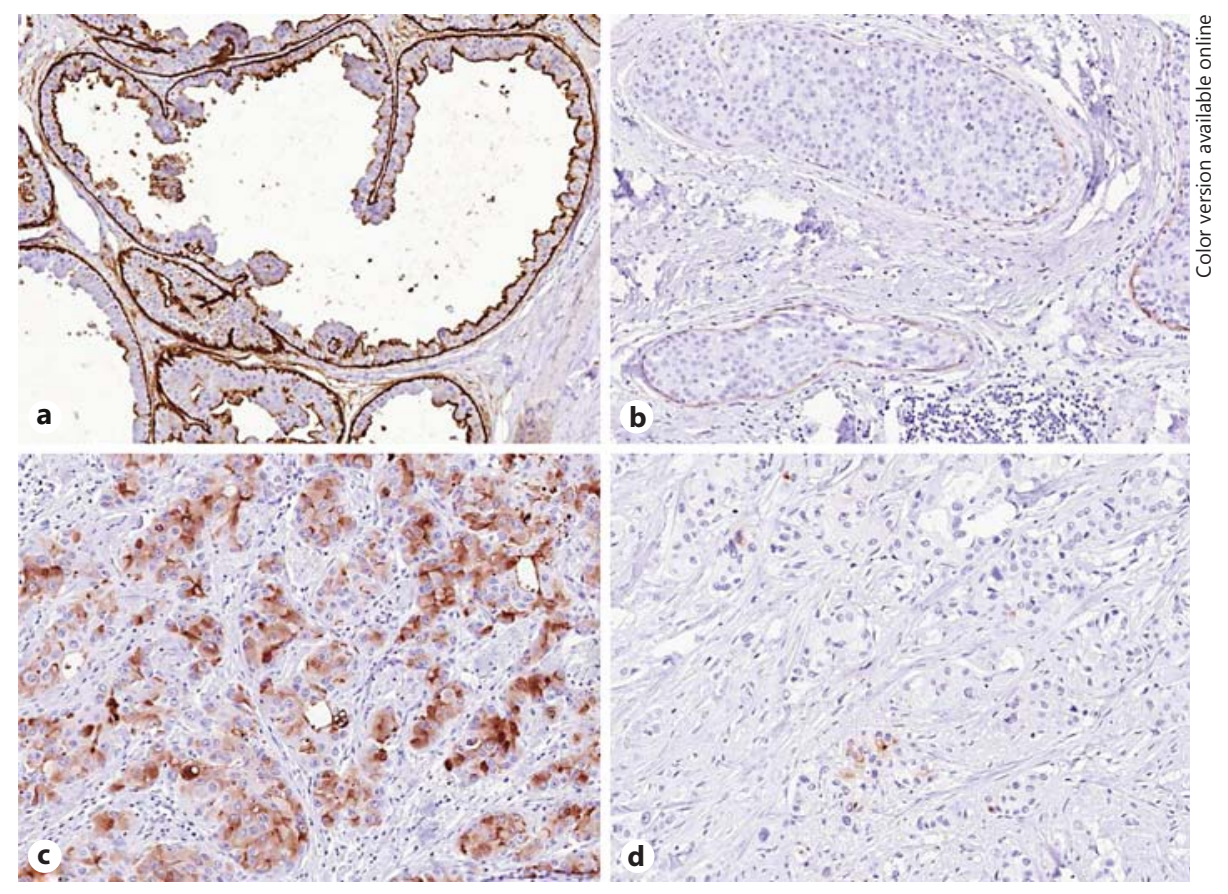

\section{Results}

Fifty apocrine lesions were included in the study: 10 cysts with or without papillary hyperplasia, 1 cyst without an MEC layer [32], 6 apocrine adenoses, 2 papillomas, 13 DCIS, 14 invasive carcinomas of no special type (formerly ductal carcinomas) and 4 invasive lobular carcinomas.

$17 / 19$ [0.89; 95\% confidence interval (CI) 0.68-0.97] benign apocrine lesions (fig. 1) showed complete or partial luminal CD10 staining (fig. 2a), although most cases included parts without staining and 2 lesions (an apocrine adenosis and a cyst with papillary hyperplasia) were completely negative (fig. 1). The MECs were often but not always positive.

As concerns malignant lesions, 8/13 apocrine DCIS cases displayed no luminal staining (fig. 2b), but 4 (0.31; 95\% CI 0.13-0.58) demonstrated very focal luminal positivity. The MECs around the DCIS showed a spectrum of staining from nil to strong and complete. Only 4/18 (0.22; 95\% CI 0.09-0.46) invasive carcinomas demonstrated lu$\mathrm{minal} / \mathrm{membranous}$ staining (fig. 1, 2c). Cytoplasmic CD10 positivity was seen focally in 4 invasive cancers (fig. 2d) and in 3 DCIS, and more markedly in 1 invasive carcinoma of no special type (fig. 2c); 2 of these invasive cancers and 1 in situ carcinoma with 'aberrant' cytoplasmic staining demonstrated no membranous staining. Benign lesions showed luminal/membranous staining more commonly than malignant ones $(17 / 19$ vs. $8 / 31$; p < $0.0001, \chi^{2}$ test with Yates correction for continuity) and this was also true for any epithelial staining including aberrant cytoplasmic labeling (17/19 vs. $11 / 31 ; p=0.0006$, $\chi^{2}$ test with Yates correction for continuity).

\section{Discussion}

The fact that CD10 is a ubiquitous enzyme found on the surface of many different normal cell types and pathologic lesions has a negative impact on its specificity and thus on its possible utility in routine histopathological differential diagnosis. Therefore, CD10 IHC reactions should be only used to answer specific differential diagnostic questions in well-known circumstances.

Overall, breast epithelium rarely expresses CD10. Only focal labeling of luminal ductal epithelium was reported by Kalof et al. [29]; the limited number of invasive and in situ carcinomas $(\mathrm{n}=46)$ that they studied were all negative. Bains and Sidhu [33] reported on a case of invasive breast carcinoma, showing cytoplasmic CD10 staining associated with an in situ component and intraductal papilloma, demonstrating the same type of labeling. Although no mention of receptor status was included in their description, on the basis of the figures, none of these lesions demonstrated the characteristic apocrine mor- 
phology. The authors concluded that $\mathrm{CD} 10$ positivity in metastatic tumors cannot rule out the breast as primary, and related the phenotype to the CD10-positive progenitor cells capable of differentiating towards luminal epithelial cells and MECs described by Stingl et al. [34].

Ductal and lobular carcinomas are rarely positive for CD10 [31], but some subsets may be different in this respect: of 40 ER-positive tumors, none demonstrated CD10 positivity (defined with a cut-off of $10 \%$ staining) and only a single case showed $<10 \%$ labeling, whereas 12 of 77 ER-negative carcinomas (16\%) showed cytoplasmic or membranous staining in $30-100 \%$ of the cells [35]. A subset of ER-negative breast cancers is also negative for progesterone receptors (PR) and human epidermal growth factor receptor-2 (Her2), and is therefore labeled as triple-negative. Some triple-negative carcinomas express basal (i.e. MEC) markers (cytokeratin 5 and/or EGFR) and this feature has been suggested for the delineation of the basal-like gene-expression profile-based subgroup of breast cancers on IHC [36]. Not surprisingly, some of these carcinomas may also express CD10, an MEC marker in a substantial number of cases (16/20 of spindle-cell metaplastic carcinomas and carcinosarcomas) [37], similarly to the rare cases that demonstrate straightforward myoepithelial differentiation [38]. Apocrine carcinomas are also generally ER-and PR-negative [39], and might have been included in previous studies of ER-negative carcinomas, but without distinct identification of this subset. Smollich et al. [40] identified cytoplasmic (and occasional membranous) CD10 (neprilysin) staining of tumor parenchymal (epithelial) cells in 33/126 (26\%) of breast cancers and found this labeling to be associated with better prognosis, in contrast to the CD10 staining of the stromal myofibroblast reported to indicate worse prognosis.
CD10 positivity has been described in benign apocrine epithelium [29, 31], but no data on CD10 expression in various other types of apocrine breast lesions have been available until now. Our results indicate that benign apocrine epithelium (metaplasia) is typically positive for CD10 with a luminal staining pattern, although there are exceptions to the rule. Malignization or apocrine differentiation in malignant lesions seems to be associated with a partial or complete loss of this staining pattern, which is therefore rarer in in situ carcinomas and even rarer in invasive ones, and cytoplasmic (aberrant) staining may also occur in this subset.

Although the staining of MECs was not the primary aim of our study, our findings are in keeping with earlier works on the subject, and suggest that the sensitivity of CD10 as an MEC marker is lower than other markers like p40 and smooth-muscle actin. Its proportional sensitivity is even further diminished in certain lesions like benign sclerosing lesions [41] and DCIS [42], known for their reduced expression of MEC markers [43]. Based on the literature $[29,30,42]$ and supported by our experience, CD10 is not an ideal myoepithelial marker. However, occasional CD10 staining of epithelial cells should be kept in mind, as its occurrence may interfere with the identification of some cells as epithelial or myoepithelial, especially in apocrine lesions, some of which may turn out to be benign, even without the presence of a myoepithelial layer $[32,44]$.

\section{Acknowledgements}

The authors acknowledge the support of the TÁMOP 4.2.4.A/211-1-2012-0001 project and KEP 2014 of the University of Szeged.

\section{References}

1 Turner AJ, Isaac RE, Coates D: The neprilysin (NEP) family of zinc metalloendopeptidases: genomics and function. Bioessays 2001;23: 261-269.

2 Roques BP, Noble F, Daugé V, Fournié-Zaluski MC, Beaumont A: Neutral endopeptidase 24.11: structure, inhibition, and experimental and clinical pharmacology. Pharmacol Rev 1993;45:87-146.

3 Maguer-Satta V, Besançon R, Bachelard-Cascales E: Concise review: neutral endopeptidase (CD10): a multifaceted environment actor in stem cells, physiological mechanisms, and cancer. Stem Cells 2011;29:389-396.
4 Barker PE, Shipp MA, D’Adamio L, Masteller EL, Reinherz EL: The common acute lymphoblastic leukemia antigen gene maps to chromosomal region 3 (q21-q27). J Immunol 1989;142:283-287.

5 D'Adamio L, Shipp MA, Masteller EL, Reinherz EL: Organization of the gene encoding common acute lymphoblastic leukemia antigen (neutral endopeptidase 24.11): multiple miniexons and separate $5^{\prime}$ untranslated regions. Proc Natl Acad Sci USA 1989;86:71037107.

6 Zhang D, Gu T, Forsberg E, Efendic S, Brismar K, Gu HF: Genetic and functional effects of membrane metalloendopeptidase on diabetic nephropathy development. Am J Nephrol 2011;34:483-490.

7 Helisalmi S, Hiltunen M, Vepsäläinen S, Iivonen S, Mannermaa A, Lehtovirta $M$, Koivisto AM, Alafuzoff I, Soininen H: Polymorphisms in neprilysin gene affect the risk of Alzheimer's disease in Finnish patients. J Neurol Neurosurg Psychiatry 2004;75:17461748.

8 Greaves MF, Brown G, Rapson NT, Lister TA: Antisera to acute lymphoblastic leukemia cells. Clin Immunol Immunopathol 1975;4: 67-84. 
9 Pesando JM, Ritz J, Lazarus H, Costello SB, Sallan S, Schlossman SF: Leukemia-associated antigens in ALL. Blood 1979;54:1240-1248.

10 Choi WW, Weisenburger DD, Greiner TC, Piris MA, Banham AH, Delabie J, Braziel RM, Geng H, Iqbal J, Lenz G, Vose JM, Hans CP, Fu K, Smith LM, Li M, Liu Z, Gascoyne RD, Rosenwald A, Ott G, Rimsza LM, Campo E, Jaffe ES, Jaye DL, Staudt LM, Chan WC: A new immunostain algorithm classifies diffuse large B-cell lymphoma into molecular subtypes with high accuracy. Clin Cancer Res 2009;15:5494-5502.

11 Deniz K, Çoban G, Okten T: Anti-CD10 (56C6) expression in soft tissue sarcomas. Pathol Res Pract 2012;208:281-285.

12 Yada K, Kashima K, Daa T, Kitano S, Fujiwara S, Yokoyama S: Expression of CD10 in basal cell carcinoma. Am J Dermatopathol 2004;26: 463-471.

13 Carrel S, Zografos L, Schreyer M, Rimoldi D: Expression of CALLA/CD10 on human melanoma cells. Melanoma Res 1993;3:319-323.

14 Cohen AJ, Bunn PA, Franklin W, Magill-Solc C, Hartmann C, Helfrich B, Gilman L, Folkvord J, Helm K, Miller YE: Variable expression in human lung, inactivation in lung cancer, and modulation of peptide-induced calcium flux. Cancer Res 1996;56:831-839.

15 Notohara K, Hamazaki S, Tsukayama C, Nakamoto S, Kawabata K, Mizobuchi K, Sakamoto K, Okada S: Solid-pseudopapillary tumor of the pancreas: Immunohistochemical localization of neuroendocrine markers and CD10. Am J Surg Pathol 2000;24:1361-1371.

16 Borscheri N, Roessner A, Rocken C: Canalicular immunostaining of neprilysin (CD10) as a diagnostic marker for hepatocellular carcinomas. Am J Surg Pathol 2001;25:1297-1303.

17 Huang WB, Zhou XJ, Chen JY, Zhang LH Meng K, Ma HH, Lu ZF: CD10-positive stromal cells in gastric carcinoma: correlation with invasion and metastasis. Jpn J Clin Oncol 2005;35:245-250.

18 Terauchi M, Kajiyama H, Shibata K, Ino K, Mizutani S, Kikkawa F: Anti-progressive effect of neutral endopeptidase 24.11 (NEP/ $\mathrm{CD} 10)$ on cervical carcinoma in vitro and in vivo. Oncology 2005;69:52-62.

19 Chu P, Arber DA: Paraffin-section detection of CD10 in 505 nonhematopoietic neoplasms. Frequent expression in renal cell carcinoma and endometrial stromal sarcoma. Am J Clin Pathol 2000;113:374-382.

20 Bircan S, Candir O, Kapucuoglu N, Serel TA, Ciris M, Karahan N: CD10 expression in urothelial bladder carcinomas: a pilot study. Urol Int 2006;77:107-113.
21 Song J, Aumüller G, Xiao F, Wilhelm B, Albrecht M: Cell specific expression of CD10/ neutral endopeptidase 24.11 gene in human prostatic tissue and cells. Prostate 2004;58: 394-405.

22 Weil M, Itin A, Keshet E: A role for mesenchyme-derived tachykinins in tooth and mammary gland morphogenesis. Development 1995;121:2419-2428.

23 Kenny AJ, O'Hare MJ, Gusterson BA: Cellsurface peptidases as modulators of growth and differentiation. Lancet 1989;2:785-787.

24 Bachelard-Cascales E, Chapellier M, Delay E, Pochon G, Voeltzel T, Puisieux A, Caron de Fromentel C, Maguer-Satta V: The CD10 enzyme is a key player to identify and regulate human mammary stem cells. Stem Cells 2010; 28:1081-1088.

25 Sapino A, Macrì L, Tonda L, Bussolati G: Oxytocin enhances myoepithelial cell differentiation and proliferation in the mouse mammary gland. Endocrinology 1993;133:838-842.

26 Makretsov NA1, Hayes M, Carter BA, Dabiri S, Gilks CB, Huntsman DG: Stromal CD10 expression in invasive breast carcinoma correlates with poor prognosis, estrogen receptor negativity, and high grade. Mod Pathol 2007; 20:84-89.

27 Iwaya K, Ogawa H, Izumi M, Kuroda M, Mukai K: Stromal expression of CD10 in invasive breast carcinoma: a new predictor of clinical outcome. Virchows Arch 2002;440:589-593.

28 Al-Masri M, Darwazeh G, Sawalhi S, Mughrabi A, Sughayer M, Al-Shatti M: Phyllodes tumor of the breast: role of CD10 in predicting metastasis. Ann Surg Oncol 2012;19:11811184.

29 Kalof AN, Tam D, Beatty B, Cooper K: Immunostaining patterns of myoepithelial cells in breast lesions: a comparison of CD10 and smooth muscle myosin heavy chain. J Clin Pathol 2004;57:625-629.

30 Dewar R, Fadare O, Gilmore H, Gown AM: Best practices in diagnostic immunohistochemistry: myoepithelial markers in breast pathology. Arch Pathol Lab Med 2011;135: 422-429.

31 NordiQC: CD10. http://www.nordiqc.org/ Epitopes/CD10/CD10.htm (accessed 9 May 2015)

32 Cserni G: Benign apocrine papillary lesions of the breast lacking or virtually lacking myoepithelial cells - potential pitfalls in diagnosing malignancy. APMIS 2012;120:249-252.

33 Bains AS, Sidhu JS: CD10 positivity in breast epithelial neoplasms. J Clin Pathol 2007;60: 958-959.
34 Stingl J, Eaves CJ, Kuusk U, Emerman JT: Phenotypic and functional characterization in vitro of a multipotent epithelial cell present in the normal adult human breast. Differentiation 1998;63:201-213.

35 Kesse-Adu R, Shousha S: Myoepithelial markers are expressed in at least $29 \%$ of oestrogen receptor negative invasive breast carcinoma. Mod Pathol 2004;17:646-652.

36 Nielsen TO, Hsu FD, Jensen K, Cheang M, Karaca G, Hu Z, Hernandez-Boussard T, Livasy C, Cowan D, Dressler L, Akslen LA, Ragaz J, Gown AM, Gilks CB, van de Rijn M, Perou CM: Immunohistochemical and clinical characterization of the basal-like subtype of invasive breast carcinoma. Clin Cancer Res 2004; 10:5367-5374.

37 Leibl S, Gogg-Kammerer M, Sommersacher A, Denk H, Moinfar F: Metaplastic breast carcinomas: are they of myoepithelial differentiation? Immunohistochemical profile of the sarcomatoid subtype using novel myoepithelial markers. Am J Surg Pathol 2005;29:347353

38 Buza N, Zekry N, Charpin C, Tavassoli FA: Myoepithelial carcinoma of the breast: a clinicopathological and immunohistochemical study of 15 diagnostically challenging cases. Virchows Arch 2010;457:337-345.

39 Vranic S, Gatalica Z, Deng H, Frkovic-Grazio S, Lee LM, Gurjeva O, Wang ZY: ER-a36, a novel isoform of ER-a66, is commonly overexpressed in apocrine and adenoid cystic carcinomas of the breast. J Clin Pathol 2011;64: 54-57.

40 Smollich M, Götte M, Yip GW, Yong ES, Kersting C, Fischgräbe J, Radke I, Kiesel L, Wülfing P: On the role of endothelin-converting enzyme-1 (ECE-1) and neprilysin in human breast cancer. Breast Cancer Res Treat 2007; 106:361-369.

41 Hilson JB, Schnitt SJ, Collins LC: Phenotypic alterations in associated with benign sclerosing lesions of the breast. Am J Surg Pathol 2010;34:896-900

42 Hilson JB, Schnitt SJ, Collins LC: Phenotypic alterations in ductal carcinoma in situ-associated myoepithelial cells: biologic and diagnostic implications. Am J Surg Pathol 2009; 33:227-232.

43 Kővári B, Szász AM, Kulka J, Marušić Z, Šarčević B, Tiszlavicz L, Cserni G: Evaluation of p40 as a myoepithelial marker in different breast lesions. Pathobiology 2015;82:165170 .

44 Cserni G: Lack of myoepithelium in apocrine glands of the breast does not necessarily imply malignancy. Histopathology 2008;52:253255 . 